\title{
Larvicidal Potentials of Three Indigenous Plants Against Malaria Vector, Anopheles Gambiae L.
}

\author{
Sulaimon Adebisi Aina ${ }^{1, *}$, Ismail Babatunde Onajobi ${ }^{2}$, Ajoke Saidat Sanusi ${ }^{3}$ and \\ Oluwatobi Shakirat Kolejo ${ }^{4}$
}

${ }^{1}$ Department of Zoology \& Environmental Biology, Olabisi Onabanjo University, Ago-Iwoye, Ogun State, Nigeria; ${ }^{2}$ Department of Microbiology, Olabisi Onabanjo University, Ago-Iwoye, Ogun State,

Nigeria; ${ }^{3}$ Department of Plant Science, Olabisi Onabanjo University, Ago-Iwoye, Ogun State, Nigeria; ${ }^{4}$ Forestry Research Institute of Nigeria State, Jericho, Ibadan, Oyo State, Nigeria

Received: July 18, 2020; Revised: November 21, 2020; Accepted: January 12, 2021

\begin{abstract}
Malaria is one of the highest causes of mortality in the populations of African, South Asia, and Latin America as it contributes a large part of the continued impoverishment of these populations. The efficacy of both the ethanolic and aqueous extracts of the fruits of Calotropis gigantea, R. Br. (Ascelepiadaceae), Aframomum melegueta K. Schum (Zingiberaceae), and seeds of Blighia sapida (Sapindaceae) were tested on the third instar larvae of Anopheles gambiae (L). $200 \mathrm{~g}$ of the blended form of each plant material was suspended in $500 \mathrm{mls}$ of water and filtered after 1 day. The filtrates were then dried to get the stock from which serial concentrations $(20,10,1,0.1 \mathrm{mg} / \mathrm{ml})$ were reconstituted. The result after a 24 hrs bioassay time shows that the A. meleguta (59.4\%) ethanolic extract with LC $_{50}$ values of $0.3 \mathrm{mg} / \mathrm{ml}$ acted most followed by its aqueous form (38.89 \%) with $\mathrm{LC}_{50} 2.57 \mathrm{mg} / \mathrm{ml}$, ethanolic extract of C. gigantea (27.78 \%) with LC 5.57 $\mathrm{mg} / \mathrm{ml}$, the ethanolic form of B. sapida (27.5\%) $6.25 \mathrm{mg} / \mathrm{ml}$ while the aqueous forms of C. gigantea and B. sapida were 6.37 at $25 \%$ and $6.5 \mathrm{mg} / \mathrm{ml}$ at $26.6 \%$ respectively. For all the plants used, A. melegueta was the most potent plant and there was significant difference $(\mathrm{p}<0.05)$ between the ethanolic extract and the aqueous form. The use of insecticides of plant origins may serve as a suitable alternative to chemical insecticides in the future with their characteristic relative safety, degradability, and abundance in many areas of the world.
\end{abstract}

Keywords: Calotropis gigantea, Aframomum melegueta, Blighia sapida, Anopheles gambiae, Ethanolic extract, Aqueous extract.

\section{Introduction}

There are approximately 3,500 species of mosquitoes grouped into 41 genera. Out of these only Anopheles is still the transmitter of human malaria (NCID, 2004). And within the genus Anopheles comprising more than 400 described species approximately, 70 species are active vectors of malaria affecting humans (Pimenta et al., 2015). The life cycle starts when the female Anopheles mosquito takes a blood meal from a Plasmodium infected vertebrate host and ingests gametocytic forms of the parasite that are present in the blood (Pimenta et al., 2015). The mosquito Anopheles gambiae is the principal vector of malaria in Africa. According to the WHO statistics, this parasitic disease infects from 300 to 500 million persons per year in the world and kills more than a million and a half each year, mainly African children (Marimo et al., 2016). Together with AIDS, malaria is one of the causes of mortality in the populations of African, South Asia, and Latin America and it contributes a large part of the causes of poverty among these populations (Aina et al, 2009a). ; it contributes a large part of the continued impoverishment of these populations (Aina et al, 2009a).
Calotropis gigantea is a large shrub growing to $4 \mathrm{~m}$ tall. Its flowers occur in waxy clusters of either white or lavender. The stem is oval with light green leaves, and milky in appearance (Li et al., 2015). The latex of $C$. gigantea contains cardiac glycosides, fatty acids, and calcium oxalate. The milky juice of Calotropis sp. was used against arthritis, cancer, and as an antidote for snakebite (Upadhyay, 2014)

A. melegueta is a perennial herbaceous plant found in swampy areas along the West African coast. Its trumpetshaped, purple flowers develop into pods $5-7 \mathrm{~cm}$ long, containing numerous small, reddish-brown seeds. The presence of aromatic ketones, such as (6)paradol (systematic name: 1-(4-hydroxy-3methoxyphenyl)-decan-3-one) caused the pungent, peppery taste of the seeds. The dominating flavor components are the essential oils which closely relate to cardsmom and occur in traces (Austin, 2004). In West African folk medicine, "grains of paradise" are valued for their warming and digestive properties, and among the Efik in Nigeria they have been used for divination and ordeals (Simmons, 1956) to determine guilt (Nwaehujor, 2014). A. melegueta was brought to the Caribbean and

\footnotetext{
*Corresponding author e-mail: : aina.sulaimon@oouagoiwoye.edu.ng.
} 
Latin America, where it is used in religious (voodoo) rites (Moret, 2013)

Blighia sapida (Fig. 3) is also known as ackee in English and locally as Okpu (Igbo), Isin (Yoruba), Ukpe (Edo) and Gwanja kusa (Hausais a fruit of the Sapindaceae soapberry family. It is native to tropical West Africa (Kristen, 2003; Simons and Leakey, 2004). The English common name is derived from the West African Akan akye fufo (Simons, and Leakey, 2004). It is used for its "soap" properties as a laundering agent or fish poison in West Africa and the Caribbean Islands. The ripe arils, leaves or bark were used to treat minor ailments in traditional African medicine (Sinmisola et al., 2019).

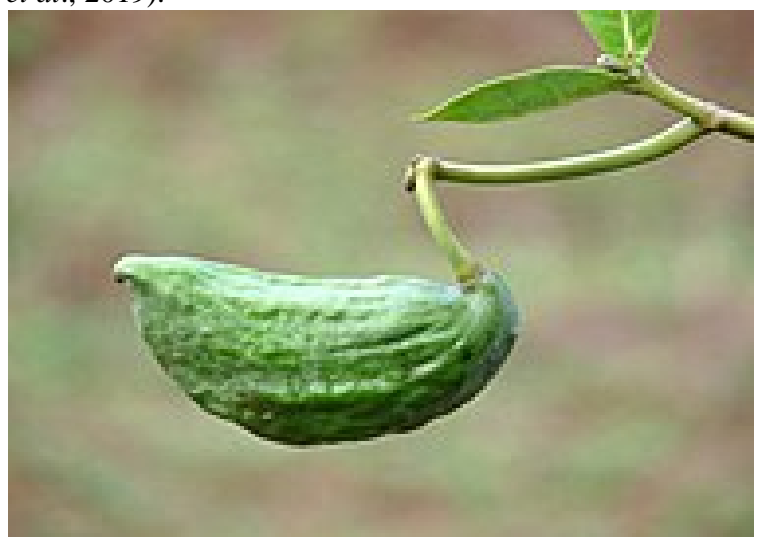

Figure 1. Calotropis gigantean fruit (Source, Whistler, 2000)

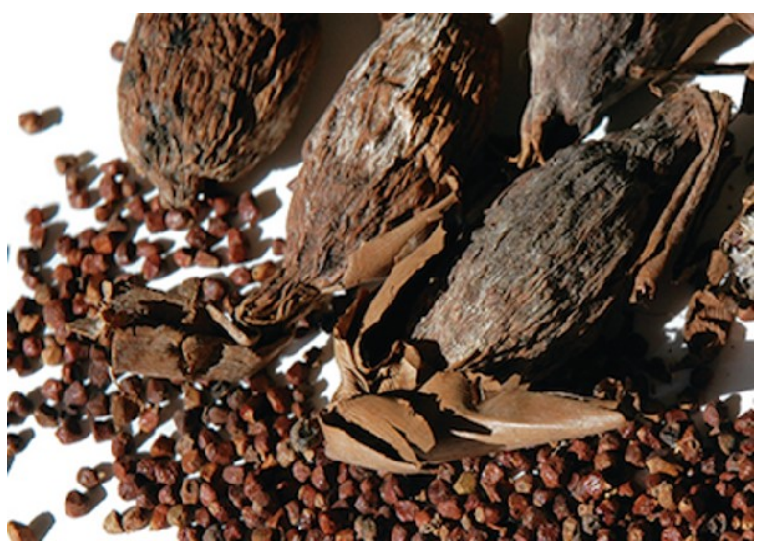

Figure 2. Aframomum melegueta fruit (Source, Osuntokun, 2020)

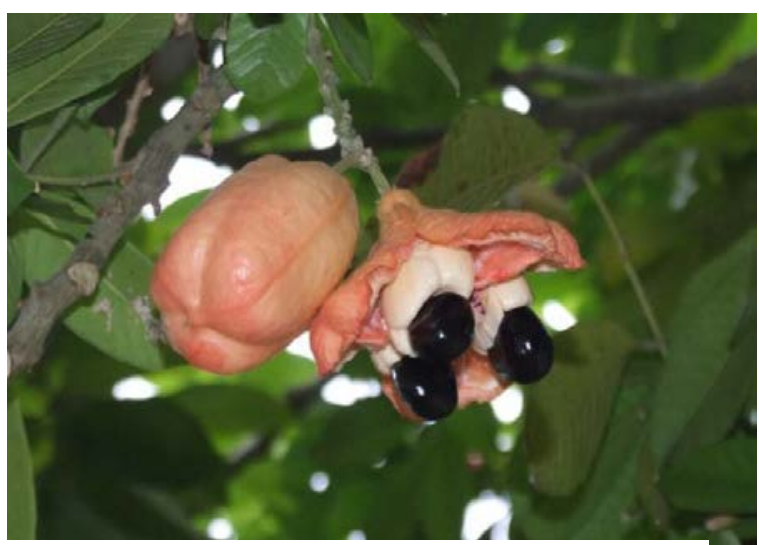

Figure 3. Bliahia sapida fruit showing seeds (black)(Source, Kristen, 2003)

At present biocontrol and biopesticide agents are only operational against mosquito larvae and pupae (Thomas, 2018). Plant materials have been used in different forms to control mosquitoes; for example, ancient peoples used smoke from burning cattle or goat dung to drive out mosquitoes from their caves or huts before sleeping (Kihampa, 2011). Later on, certain herbs and barks of some trees were added to the smoldering fire to enhance the repellent action of smoke. A large number of plant extracts have been reported to have mosquitocidal or repellent activity against mosquito vectors but very few plant products have shown practical utility for mosquito control (Mohan and Ramaswamy, 2007).

Botanical insecticides are made from chemical extracts from plants. Examples are Pyrethrum which is an insecticide derived from the dried flower of Chrysanthemum cinerariaefolium grown in Kenya, Australia, and Tanzania. Pyrethrins are chemicals extracted from the pyrethrum flower, Rotenone is extracted from the roots of several tropical legumes such as the cube plant grown in Peru, originally used in India as a fish poison but moderately toxic to human (Sola et al., 2014).

Therefore, the objective of this study is to investigate the effects aqueous and ethanolic extracts of the fruits of Calotropis gigantea, R. Br. (Ascelepiadaceae), Aframomum melegueta K. Schum (Zingiberaceae), and seeds of Blighia sapida (Sapindaceae) on third instar larvae (Aina et al, 2009a) of Anopheles gambiae (L) to discover more plant products that can be used to control the prevalence of malaria in developing nations.

\section{Materials and Methods}

\subsection{Experimental Site}

The research was conducted at the insectaries of the Department of Zoology and Environmental Biology, Olabisi Onabanjo University, Ago-Iwoye, Ogun State, Nigerian located on Lat.6.942374, Long 3.921517.

\subsection{Collection of Plant Materials}

The matured fruits of $A$. melegueta were bought in from Awolowo Market in Sagamu, while the matured fruits of C. gigantea and the seeds of B. sapida were collected at Sagamu and Ago-Iwoye respectively, both in the Ogun State, Southwestern Nigeria. The materials were also dried in the Gallemhamp oven (Aina et al., 2009b; Ariyo et al, 2011) and identification of the plants was done at the Herbarium of the Department of Plant Science, OOU, Ago-Iwoye.

\subsection{Culture of Mosquito}

The $3^{\text {rd }}$ instar Anopheles gambiae mosquito larvae used for this study was collected from a culture maintained in the insectary of the Department of Zoology and Environmental Biology, OOU, Ago-Iwoye, Nigerian. The third stage of larvae development is identified morphologically (according to Gillies and Coetzee, 1987) using dissecting microscope to examine characters like: length between 3 and $5 \mathrm{~mm}$, well developed palmate hairs, widened sclerotized head collar and long lateral setae (tufty at thoracic region).

\subsection{Aqueous Extraction Preparation}

The plant materials were blended using the Moulinex blender (LM243027). 200 grams of each grounded botanical was then soaked separately in $500 \mathrm{mls}$ distilled 
water for 1 hour to dissolve the active components for 24 hrs. The suspension was then filtered using the Whatman's No.1 filter paper. The filtrate was freeze-dried to remove the water solvent in each case using the Edwards Modulyo Freeze-drying machine. From the freeze-dried (Stock), serial dilutions were made to obtain different concentrations of 20,10,1, $0.1 \mathrm{mg} / \mathrm{ml}$ (Ijarotimi et al., 2013).

\subsection{Ethanolic Extraction Preparation}

Two hundred grams (200 g) of each blended material was mixed with $500 \mathrm{mls}$ of $70 \%$ ethanol in separate jars and allowed to stay for 24 hrs. They were then filtered into separate conical flasks using the Whatman's No.1 filter paper and the filtrates were put into the Gallenhamp Vacuum oven to evaporate the extraction solvent (Aina et $a l, 2009$ a). Serial dilutions were made from the stock to obtain different concentrations of 20,10, $1,0.1 \mathrm{mg} / \mathrm{ml}$ $\mathrm{mg} / \mathrm{ml}$ (Ijarotimi et al., 2013).

\subsection{Bioassay of Extracts}

Ten active third instar larvae of the Anopheles gambiae were transferred into $(100 \mathrm{ml})$ containers containing $2 \mathrm{ml}$ of distilled water and $50 \mathrm{ml}$ from each graded concentrations of each extract was added. In the controls, the larvae were put in $50 \mathrm{ml}$ of distilled water and $2 \%$ ethanol respectively. Three replicates were set-up for each concentration including the control. The set up was allowed to stay undisturbed for 24 hours, after which the larvae were put inside distilled water to observe any recovery. A time of 5 minutes was given to observe such recovery in each treatment. Larvae were counted as dead when they were not coming to the surface for respiration and were probe insensitive. The percentage mortality was reported from the average of three replicates.

\section{Percentage mortality $=\frac{\text { Number of dead larvae }}{\text { Number of larvae introduced }} \times 100$ \\ 2.7. Statistical Analysis}

Data recorded from the bioassay tests were analyzed using probit analysis based on the Statistical Analysis System (SAS) version 16. Comparison among seeds, fruits, between seeds and fruits, and all the plants were also sorted-out using the Analysis of Variance (ANOVA) and Turkey's multiple comparison test for post hoc comparison which were carried out using SPSS for windows version 21 .

Table 2. Comparison between the ethanolic and aqueous extract for each plant

\begin{tabular}{|c|c|c|c|c|c|c|c|}
\hline & $\begin{array}{c}\text { Levene's Test for } \\
\text { Equality of } \\
\text { Variances } \\
\end{array}$ & & $\begin{array}{c}\text { t-test for } \\
\text { Equality of } \\
\text { Means }\end{array}$ & & & & \\
\hline \multirow{3}{*}{ C. gigantea } & $\mathbf{F}$ & Sig. & $t$ & df & Sig. (2-tailed) & Mean Difference & Std. Error Difference \\
\hline & .089 & .767 & .298 & 70 & .767 & .2778 & .93232 \\
\hline & & & .298 & 69.963 & .767 & .2778 & .93232 \\
\hline \multirow[t]{2}{*}{ B.sapida } & .103 & .749 & -.089 & 70 & .929 & -.0833 & .93637 \\
\hline & & & -.089 & 69.872 & .929 & -.0833 & .93637 \\
\hline \multirow[t]{2}{*}{ A. melegueta } & .595 & .443 & -2.023 & 70 & .470 & -2.0556 & 1.01631 \\
\hline & & & -2.023 & 69.796 & .470 & -2.0556 & 1.01631 \\
\hline
\end{tabular}

For the percentage mortality, Table 1 shows that of $A$. melegueta $(59.44 \%)$ fruits extracted with ethanol give the highest mortality followed by its aqueous form (38.89\%), ethanolic extract of the fruits of C. gigantea (27.78\%), ethanolic extract of $B$. sapida (27.5\%) seeds, the aqueous extract of $B$. sapida (26.67\%) while the least mortality was recorded for C. gigantea (25\%). The $\mathrm{LC}_{50}$ values indicated that the ethanolic extract of $A$. melegueta $(0.30 \mathrm{mg} / \mathrm{ml})$ was the most active followed in descending order by its aqueous form $2.57 \mathrm{mg} / \mathrm{ml}$, ethanolic extract of fruits of $C$. gigantea, ethanolic extract of seeds of $B$. sapida $(6.25 \mathrm{mg} / \mathrm{ml})$, and aqueous extract of $C$. gigantea $(6.37 \mathrm{mg} / \mathrm{ml})$ while the aqueous form of $B$. sapida $(6.5 \mathrm{mg} / \mathrm{ml})$ was least in performance.

Table 1. Percentage Mortality of A. gambiae larvae tested with ethanolic extract and water of the plants

\begin{tabular}{lllll}
\hline $\begin{array}{l}\text { Extraction } \\
\text { medium }\end{array}$ & Plant species & $\begin{array}{l}\text { Part } \\
\text { used }\end{array}$ & $\begin{array}{l}\text { Total mortality } \\
(360) \text { and } \% \\
\text { mortality }\end{array}$ & $\begin{array}{l}\mathrm{LC}_{50} \\
(\mathrm{mg} / \mathrm{ml})\end{array}$ \\
\hline \multirow{6}{*}{ Ethanol } & B. sapida & Seed & $99(27.50 \%)$ & 6.25 \\
& C. gigantea & Fruit & $100(27.78 \%)$ & 5.57 \\
& A. melegueta & Fruit & $214(59.44 \%)$ & 0.30 \\
& Control & NA & $0(0.00 \%)$ & 0.00 \\
\hline \multirow{4}{*}{ Water } & B. sapida & Seed & $96(26.67 \%)$ & 6.50 \\
& C. gigantea & Fruit & $90(25.00 \%)$ & 6.37 \\
& A. melegueta & Fruit & $140(38.89 \%)$ & 2.57 \\
& Control & NA & $0(0.00 \%)$ & 0.00 \\
\hline
\end{tabular}

Note NA - Not applicable

Table 2 shows the comparisons between the ethanolic and aqueous extracts of each plant; there were no extract for each of the plants; $C$. giganteae ( $\mathrm{P}=0.767), B$. sapida $(\mathrm{P}=0.749)$ and $A$. melegueta $(0.443$. While in Tables 3 there was no significant difference in the toxicity of the ethanolic extracts of all the plants $(P=0.377)$, but in contrast there was significant difference among the aqueous extracts of the plants $(\mathrm{P}=0.001)$ and between the ethanolic and aqueous groups $(\mathrm{P}=0.028)$. The post hoc test shows that only $A$. melegueta had a significant difference $(0.00)$ with the two other plants, which shows that it is most potent using Fisher's LSD (Table 4). significant differences between the ethanolic and aqueous 
Table 3. Comparison within each extraction medium and between the ethanolic and aqueous groups.

\begin{tabular}{|c|c|c|c|c|c|c|}
\hline & & Sum of Squares & df & Mean Square & $\mathbf{F}$ & Sig. \\
\hline & Between Groups & 32.889 & 2 & 16.444 & .986 & .377 \\
\hline \multirow[t]{3}{*}{ Ethanolic extract } & Within Groups & 1751.778 & 105 & 16.684 & & \\
\hline & Total & 1784.667 & 107 & & & \\
\hline & Between Groups & 265.574 & 2 & 132.787 & 7.969 & .001 \\
\hline \multirow[t]{2}{*}{ Aqueous extract } & Within Groups & 1749.639 & 105 & 16.663 & & \\
\hline & Total & 2015.213 & 107 & & & \\
\hline Ethanolic versus Aqueous & Between Groups & 20.782 & 1 & 20.782 & 1.170 & .028 \\
\hline \multirow[t]{2}{*}{ media } & Within Groups & 3799.880 & 214 & 17.756 & & \\
\hline & Total & 3820.662 & 215 & & & \\
\hline
\end{tabular}

Table 4. Post Hoc Tests for Multiple Comparisons

\begin{tabular}{|c|c|c|c|c|}
\hline & Comparison & Mean D & eStd. Error & Sig. \\
\hline Duncan & $C-A$ & -2.8704 & 0.6298 & 0 \\
\hline & $C-B$ & -3.7002 & 0.6298 & 0.953 \\
\hline & $A-B$ & 2.8333 & 0.6298 & 0 \\
\hline
\end{tabular}

* The mean difference is significant at the .05 level. C Calotropis gigantean; A - Aframonum melegueta; B - Blighia sapida

\section{Discussion}

Challenges posed by high cost and development of resistance in many vector mosquito species to many of the patented synthetic insecticides have revived interest in exploring the pest control potentials of botanicals (Karunamoorthi et al., 2008; Karunamoorthi, 2012). Also, the tendency toward the use of "soft" pesticides was encouraged by the economic and environmental concerns about chemicals (Awad and Shimaila, 2003; Sharma et al., 2016).

The assessment of botanicals for the three plant extracts shows that the ethanolic and aqueous extracts of $A$. melegueta were the most effective for the control of $A$. gambiae larvae; this could be due to the similarity shared between the two extracted components of the plants based on the solvent type used while the aqueous extract of $C$. gigantea was the least to pose mortality. This is in line with the report of (Oke et al., 2001) in which the hexanolic extract of $P$. guineense kills both $77 \%$ and $95 \%$ of the Aedes aegypti larvae in 1hour and 24 hours respectively. Fafioye et al. (2004) reported that the ethanolic extracts of Parkia biglobosa and $R$. vinifera were more potent against the juveniles of Clarias gariepinus than the aqueous forms. This is due to the polarity, volatility, and its (ethanol) power to dissolve more of the active constituents. Also, the extract of Cannabis sativa (Moraceae) tested on Anopheles stephensi within 24 and 48hours gave $\mathrm{LC}_{50}$ of 15.58 and 8.04ppm respectively (Maurya et al., 2007; Aina et al, 2009a).

This result falls in line with the study of Ileke et al. (2017) who reported that the leaf and seed of A. melegueta were screened for their potential larvicidal and pupicidal properties against Anopheles species in the laboratory. After a 24 hrs bioassay time, larval and pupal mortalities increased with increase in concentration irrespective of the type of plant part used for the extraction while the seed extract showed more insecticidal effect on both larvae and pupae of Anopheles species. The powder of A. melegueta posed high mortality in adult Sitophilus zeamais within 24hours ( $\mathrm{LC}_{50}$ of $0.398 \mathrm{~g} / 5 \mathrm{~g}$ maize) (Ribeiro et al., 2017). The mosquitocidal effect of acetone extract of Cymbopogon citratus (DC). Stapf., Momordica charantia L., Zingiber officinale (Rof), Xylopia aethiopica (Dunl). A. Rich., Ocimum gratissimum L. and A. melegueta (Ros) K. Schum tested against the cowpea aphid, Aphis craccivora Koch was investigated. Extracts from $Z$. officinale and $A$. melegueta had the greatest effect in causing mortality of $A$. craccivora and also hindered its reproduction (Karunamoorthi and Ilango, 2010).

Govidarajam and Sivakamar, 2014 reported the efficacy of Eeythrina indica (Lam.) on Anopheles stephensi, Aedes aegypti, and Culex quinquefasciatus larvae using hexane, benzene, chloroform, ethyl acetate and methanol as solvents for extraction. After $24 \mathrm{hrs}$ of the bioassay, all the extracts showed high larvicidal effects.

The oil extract of Citrus hystrix (Kaffir lime) oil exhibits highest repellency activity (95.33\%) against German cockroach (Blattella germanica) over the oils of Cymbopogon winteruanus (Citronella) and Eucalyptus globulus (Eucalyptus) in which both had $85.00 \%$ mortality (Chooluck et al., 2019, while by comparison the hexane and ethanol extracts of Achyranthus aspera had highest Larvicidal potentials with $\mathrm{LC}_{50}$ value of $82.555 \mathrm{ppm}$ and $68.133 \mathrm{ppm}$ over those of Cassia occidentalis, Catharanthus roseus, Lantana camara and Xanthium strumarium.

\section{Conclusion}

Although the statistical analysis revealed that the ethanolic extraction is better in performance, this does not mean that we cannot also use the aqueous form for such control. There is still a need to investigate the use of other volatile solvents to discover the unknown properties of these plants. Invariably, botanical insecticides may serve as suitable alternative to synthetic insecticides in the future as they are safer, easily degradable, and are readily found in many areas of the world (Sreedhanya et al., 2017).

\section{Competing interests}

The author(s) declare that they have no competing interests. 


\section{Authors' contributions}

SAA, ASS and OSK conducted the experiments and drafted the manuscript. IBO participated in the writing of the final versions of the manuscript and provided other logistical issues towards the publication of the article. SAA also oversaw the acquisition of laboratory requirements and provision of literature.

\section{Acknowledgments}

The authors appreciate Prof. O.O. Fafioye, Head, Department of Zoology and Environmental Biology, Olabisi Onabanjo University, Ago-Iwoye for allowing the use of the insectaries in the Animal House. Also, we thank Alhaja Hamdallat Funke Aina who assisted in purchasing the fruits of $A$. melegueta from markets and locating the plants for procurement.

\section{References}

Aina SA, Banjo AD, Lawal OA, and Jonathan K. 2009b. Efficacy of some Plant Extracts on Anopheles gambiae Mosquito larvae. Acad. J. Entomol., 2(1): 31-35.

Aina SA, Banjo AD, Lawal OA, Okoh HI, Aina OO and Dedeke GA. 2009a. The toxicity of extracts of Tetrapleura tetraptera (Aridan), Delonix regia (Flame of the Forest) and Raphia vinifera (Raffia Palm) on the larvae of Anopheles gambiae. Acad $J$ Entomol., 2(2): 67-70.

Ariyo OA, Shonubi OO, Oyesiku OO and Akande AO. 2011. Antimicrobial activity of the indigenous liverwort, Riccia nigerica Jones, from Southwestern Nigeria. Evansia, 28(2): 43-48.

Austin D. 2004. "Florida ethnobotany". CRC Press, p. 170. ISBN 0-8493-2332-0.

Awad OM and Shimaila A. 2003. Operational use of neem oil as an alternative anopheline larvicide. Part A: Laboratory and field efficacy. East Mediterr Health J., 9(4): 637-45.

Chooluck K, Teeranachaideekul V, Jintapattanakit A, Lomarat P and Phechkrajang C. (2019). Repellency effects of essential oils of Cymbopogon winterianus, Eucalyptus globulus, Citrus hystrix and their major constituents against adult German cockroach (Blattella germanica) Linnaeus (Blatteria: Blattellidae). Jordan J Biol Sci., 12(4): 519-521.

Fafioye OO, Adebisi AA and Fayode SO. 2004. Toxicity of Parkia biglobosa and Raphia vinifera extracts on Clarias gariepinus juveniles. Afric J Biotech., 3(10): 627-630.

Gillies MT and Coetzee M. 1987. A supplement to the Anophelinae Africa South of the Sahara (Afrotropical region), Johannesburg, South Africa. S Afr Inst Med Res., 55:1-143.

Govindarajan M and Sivakumar R. 2014. Larvicidal, ovicidal, and adulticidal efficacy of Erythrina indica (Lam.) (Family: Fabaceae) against Anopheles stephensi, Aedes aegypti, and Culex quinquefasciatus (Diptera: Culicidae). Parasitol Research., 113: 777-791.

Ijarotimi OS, Adeoti OA and Ariyo O. 2013. Comparative study on nutrient composition, phytochemical, and functional characteristics of raw, germinated, and fermented Moringa oleifera seed flour. Food Sci \& Nutrition., 1(6): 452-463. https://doi.org/10.1002/fsn3.70.

Ileke KD, Adesina JM and Okunola OG. 2017. Larvicidal and pupicidal potential of Aframomum melegueta K. Schum extract against mosquito, Anopheles species. J Entomol Res Soc., 19(1): 121-127.
Karunamoorthi K and Ilango K. 2010. Larvicidal activity of Cymbopogon citratus (DC) Stapf. and Croton macrostachyus Del. against Anopheles arabiensis Patton, a potent malaria vector. Euro Rev Med \& Pharmacol Sciences., 14(1): 57-62 PMID: 20184090.

Karunamoorthi K, Ramanujam S and Rathinasamy R. 2008. Evaluation of leaf extracts of Vitex negundo L. (Family: Verbenaceae) against larvae of Culex tritaeniorhynchus and repellent activity on adult vector mosquitoes. Parasitol Res., 103: 545. https://doi.org/10.1007/s00436-008-1005-5

Karunamoorthi K. 2012. Medicinal and aromatic plants: a major Source of green pesticides/ risk reduced pesticides. Med Aromat Plants., 1: 8 doi: 10.4172/2167-0412.1000e137.

Kihampa C. 2011. Tanzanian botanical derivatives in the control of malaria vectors: opportunities and challenges. J Appl Sci Environ Mgt., 15: 155-160.

Kristen L. 2003. Tropical Flowering Plants: A Guide to Identification and Cultivation. Timber Press. ISBN 0-88192585-3.

Li B, Gilbert MG and Stevens WD. 2015, "Calotropis gigantea (Linnaeus) W. T. Aiton, Hortus Kew. ed. 2. 2: 78. 1811", Flora of China online, retrieved 19 July2015.

Marimo P, Hayeshi R_and Mukanganyama S. 2016. Inactivation of Anopheles gambiae glutathione transferase $\varepsilon 2$ by epiphyllocoumarin. Biochem Res Int., 2016: 2516092. doi: 10.1155/2016/2516092. PMCID: PMC4746303. PMID: 26925266.

Maurya P, Mohan L, Sharma P, Batabyal L and Srivastara CN. 2007. Larvicidal efficacy of Aloe barbadensis and Cannabis sativa against the malaria vector Anopheles stephensi (Diptera: Culicidea). Entomol Research J., 37(3): 153-156.

Mohan DR and Ramaswamy M. 2007. Evaluation of larvicidal activity of the leaf extract of a weed plant, Ageratina adenophora, against two important species of mosquitoes, Aedes aegypti and Culex quinquefasciatus. Afric J Biotech., 6(5): 631-638. Available online at http://www.academicjournals.org/AJB.

Moret ES. 2013. Trans-Atlantic Diaspora Ethnobotany: Legacies of West African and Iberian Mediterranean Migration in Central Cuba. In: Voeks R., Rashford J. (eds) African Ethnobotany in the Americas. Springer, New York, NY. https://doi.org/10.1007/978-1-4614-0836-9_9. ISBN 9781-4614-0835-2.

National Centre for Infectious Diseases (NCID). 2004. Mosquitoes. Division of parasitic diseases, Atlanta, 6pp. https://www.ncid.sg (July 17, 2020).

Nwaehujor CO, Eban LK, Ode JO, Ejiofor CE and Igile GO. 2014. Hepatotoxicity of Methanol Seed Extract of Aframomum melegueta [Roscoe] K. Schum. (Grains of paradise) in SpragueDawley Rats. Am J Biomed Research., 2(4): 61-66. doi: 10.12691/ajbr-2-4-1.

Oke OA, Anyale OO, Amusan AAS, and Okorie TG. 2001. Toxicity of Hexanolic extract of Piper guineense Schum \& Thunn (Piperaceae) seed oil to larvae of Aedes aegypti (L). European $J$ Sci Research., 18(1): 6-11.

Osuntokun OT. 2020. Aframomum melegueta (grains of paradise). Ann Microbiol \& Infectious Dis., 3(1): 1-6. ISSN 26375346.

Pimenta PFP, Orfano AS, Bahia AC, Duarte APM, RíosVelásquez CM, Melo FF, Pessoa FAC, Oliveira GA, Campos KMM, Villegas LM, Rodrigues NB, Nacif-Pimenta R, Simões RC, Monteiro WM, Amino R, Traub-Cseko YM, Lima JBP, Barbosa MGV, Lacerda MVG, Tadei WP and Secundino NFC. 2015. An overview of malaria transmission from the perspective of Amazon Anopheles vectors. Mem Inst Oswaldo Cruz., 110(1): 23-47. doi: 10.1590/0074-02760140266. PMCID: PMC4371216. 
Ribeiro AV, Luz CEA, Bastos CS, Krieger YST, Da Silva NH and Da Silva WB. 2017. Toxicity of botanical and synthetic formulations to the maize weevil, Sitophilus zeamais (Coleoptera: Curculionidae). Revist Colombiana de Entomol., 43(2): 167-172. DOI: $10.25100 /$ socolen.v43i2.5938.

Sharma A, Kumar S and Tripathi P. (2016). Evaluation of the larvicidal efficacy of five indigenous weeds against an Indian strain of dengue vector, Aedes aegypti L. (Diptera: Culicidae). J Parasitol Res., 2857089. http://dx.doi.org/10.1155/2016/2857089.

Simons AJ and Leakey RRB. 2004. Tree domestication in tropical agroforestry. Agroforestry Sys., 61-62: 167-181.

Sinmisola A, Oluwasesan BM and Chukwuemeka AP. 2019. "Blighia sapida K.D. Koenig: A review on its phytochemistry, pharmacological and nutritional properties". J Ethnopharm., 235 446-459. doi: 10.1016/j.jep.2019.01.017.
Sola P, Mvumi BM, Ogendo JO, Mponda O, Kamanula JF, Nyirenda SP, Belmain SR and Stevenson PC. 2014. Botanical pesticide production, trade and regulatory mechanisms in subSaharan Africa: making a case for plant-based pesticidal products. Food Sec., 6(3): 369-384. DOI: 10.1007/s12571-014-0343-7.

Sreedhanya S, Athira A and Pushpalatha E. 2017. Larvicidal and repellent efficacy of some of the weed plant extracts against Culex quinquefasciatus Say. J Adv Lab Research Biol., 8(1): 6-11. ISSN: 0976-7614.

Thomas MB. 2018. Biological control of human disease vectors: a perspective on challenges and opportunities. BioControl, 63: 6169. https://doi.org/10.1007/s10526-017-9815-y.

Upadhyay RK. 2014. Ethnomedicinal, pharmaceutical and pesticidal uses of Calotropis procera (Aiton) (Family: Asclepiadaceae). Int J Green Pharm., 8: 135-46.

Whistler WA. 2000. Tropical Ornamentals; A Guide. Timber Press Inc. Oregon. ISBN 0-88192-448-2. 